\title{
Disclosure of Article Funding and Conflicts of Interest in High-Impact Clinical Journals
}

\author{
Timothy S. Anderson, MD, MAS ${ }^{1,2}$ (D), Colette DeJong, MD ${ }^{3}$, Chester B. Good, MD, MPH \\ and Walid F. Gellad, MD, MPH ${ }^{5}$
}

'Division of General Medicine, Beth Israel Deaconess Medical Center, Boston, MA, USA; ${ }^{2}$ Division of General Internal Medicine, University of California, San Francisco, San Francisco, CA, USA; ${ }^{3}$ Department of Medicine and Center for Healthcare Value, Philip R. Lee Institute for Health Policy Studies, University of California, San Francisco, San Francisco, CA, USA; 'Division of General Internal Medicine, University of Pittsburgh, Pittsburgh, PA, USA; ${ }^{5}$ Division of General Internal Medicine and Center for Pharmaceutical Policy and Prescribing, University of Pittsburgh, Pittsburgh, PA, USA.

J Gen Intern Med 35(4):1345-7

DOI: $10.1007 / \mathrm{s} 11606-019-05378-9$

(c) Society of General Internal Medicine 2020

\section{INTRODUCTION}

In light of strong evidence that financial relationships with industry may influence the conduct and reporting of clinical research, there has been a call for greater transparency via disclosure of financial conflicts of interest (COI). ${ }^{1}$ Accurate disclosure of study funding and authors' financial relationships provides editors, reviewers, and readers with key information when evaluating study results and is recommended by EQUATOR reporting guidelines for trials, observational studies, systematic reviews, and clinical practice guidelines. ${ }^{2}$ However, the rate at which journals disclose funding and COI information in published articles is unknown. We therefore examined a cross section of high-impact clinical journals to determine the inclusion of funding and disclosure statements within articles and whether these practices varied by article type and clinical field.

\section{METHODS}

Similar to prior studies, ${ }^{3}$ we examined the highest-impact clinical journals based on 2015 Journal Citation Reports categories and impact factor rankings. ${ }^{4}$ We included 34 journals, consisting of 5 general interest journals, 11 internal medicine, 11 surgical, and 7 non-medicine non-surgery specialty journals. Specialties were selected by size based on number of active physicians. ${ }^{5}$

For each journal, we examined all original clinical research, review, and opinion articles published in the first issue of 2015. Individual article data was independently abstracted from online articles between January and June 2017. To identify all text related to funding and financial relationships, we searched each article electronically for the phrases

Received June 28, 2019

Accepted September 12, 2019

Published online February 3, 2020 "disclosure," "funding," "support," "conflict of interest," "acknowledge" and "financial."

We present descriptive statistics of article types and prevalence of funding and COI statements, overall and by journal specialty and article type.

\section{RESULTS}

The mean number of articles per journal was 24 (range 6 to 67). A total of 800 articles met inclusion criteria, of which $57 \%$ were research studies, $22 \%$ were opinion pieces, and $11 \%$ were reviews (Table 1 ).

Nearly half of articles did not include a funding statement $(382 / 800,48 \%$; Table 2). A larger proportion of articles in surgery journals $(62 \%)$ lacked a funding statement compared with general interest $(42 \%)$, internal medicine $(35 \%)$, and other specialty journals (30\%). Few articles included a statement that they received only internal institutional funding (4\%) or no funding (3\%). A larger proportion of opinion articles lacked a funding statement (82\%) compared with review articles $(43 \%)$ and original research articles $(37 \%)$.

The majority of articles included a statement regarding authors' disclosure of COI (673/800, 84\%; Table 2); however, $\mathrm{COI}$ statements were less common in surgery journals $(73 \%$ vs 93-99\% of other journal categories). Most articles with COI statements included the statement within the article itself (612/ $673,91 \%$ ); however, $9 \%$ included only a link to an online repository.

\section{DISCUSSION}

Our analysis of high-impact clinical journal articles reveals that though the majority of journal articles include a published statement on COI, nearly half of published articles lacked a specific funding statement.

The International Committee of Medical Journal Editor guidelines advise journals to publish statements describing external article funding as part of COI disclosures; however, recommendations for documentation are less clear for articles receiving no external funding. Our findings 
Table 1 Article Characteristics

\begin{tabular}{|c|c|c|c|c|c|}
\hline & Total $^{\mathrm{a}}$ & General interest & Internal medicine & Surgery & Other specialty \\
\hline Articles, No. (\%) & 800 & 52 & 210 & 395 & 143 \\
\hline Articles per journal, mean (range) & $24(6-67)$ & $10(6-30)$ & $19(11-36)$ & $36(9-67)$ & $20(11-26)$ \\
\hline Original research, No. $(\%)$ & $534(67)$ & $18(35)$ & $125(60)$ & $293(74)$ & $98(69)$ \\
\hline Clinical trial & 97 & 6 & 22 & 51 & 18 \\
\hline Observational study & 424 & 12 & 99 & 238 & 75 \\
\hline Other $^{\mathrm{b}}$ & 13 & 0 & 4 & 3 & 5 \\
\hline Review, No. (\%) & $87(11)$ & $10(19)$ & $26(12)$ & $35(9)$ & $16(11)$ \\
\hline Systematic review & 37 & 2 & 10 & 17 & 8 \\
\hline Narrative review & 50 & 8 & 16 & 18 & 8 \\
\hline Opinion, No. (\%) & $179(22)$ & $24(46)$ & $59(28)$ & $67(17)$ & $29(20)$ \\
\hline Editorial & 121 & 10 & 42 & 51 & 18 \\
\hline Perspective & 55 & 13 & 16 & 16 & 10 \\
\hline Guideline & 3 & 1 & 1 & 0 & 1 \\
\hline
\end{tabular}

${ }^{a}$ General interest journals included the New England Journal of Medicine, Lancet, Journal of the American Medical Association, British Medical Journal, and PLoS Medicine. Internal medicine journals included the Journal of Clinical Oncology, Gastroenterology, Journal of the American College of Cardiology, JAMA Internal Medicine, American Journal of Respiratory \& Critical Care Medicine, Clinical Infectious Diseases, Journal of the American Society of Nephrology, Arthritis \& Rheumatology, Journal of Clinical Endocrinology \& Metabolism, and Annals of Family Medicine. Surgical journals included the Annals of Surgery, Ophthalmology, Obstetrics \& Gynecology, Journal of Urology, Journal of the American College of Surgeons, Plastic and Reconstructive Surgery, Neurosurgery, Journal of Vascular Surgery, Clinical Orthopaedics \& Related Research, Annals of Thoracic Surgery, and Head \& Neck. For the specialty of orthopedics, online disclosure forms from the highest-impact journal were not accessible; thus, the next highestimpact journal was included. Other specialty journals included JAMA Psychiatry, Annals of Neurology, JAMA Pediatrics, Radiology, Journal of the American Academy of Dermatology, Anesthesiology, and Annals of Emergency Medicine

${ }^{b}$ Other original research articles include modeling studies and pre-clinical drug trials

suggest that many journals omit negative funding statements or subsume them within the COI statement. To avoid incorrect assumptions by readers, journal policies and ICMJE guidelines could be improved by clarifying the requirement for all published articles to include both a COI statement and a distinct funding statement (specifying external funding sources, institutional funding, or no funding received).

Table 2 Article Funding and Conflict of Interest Disclosure, by Journal Specialty and Article Type

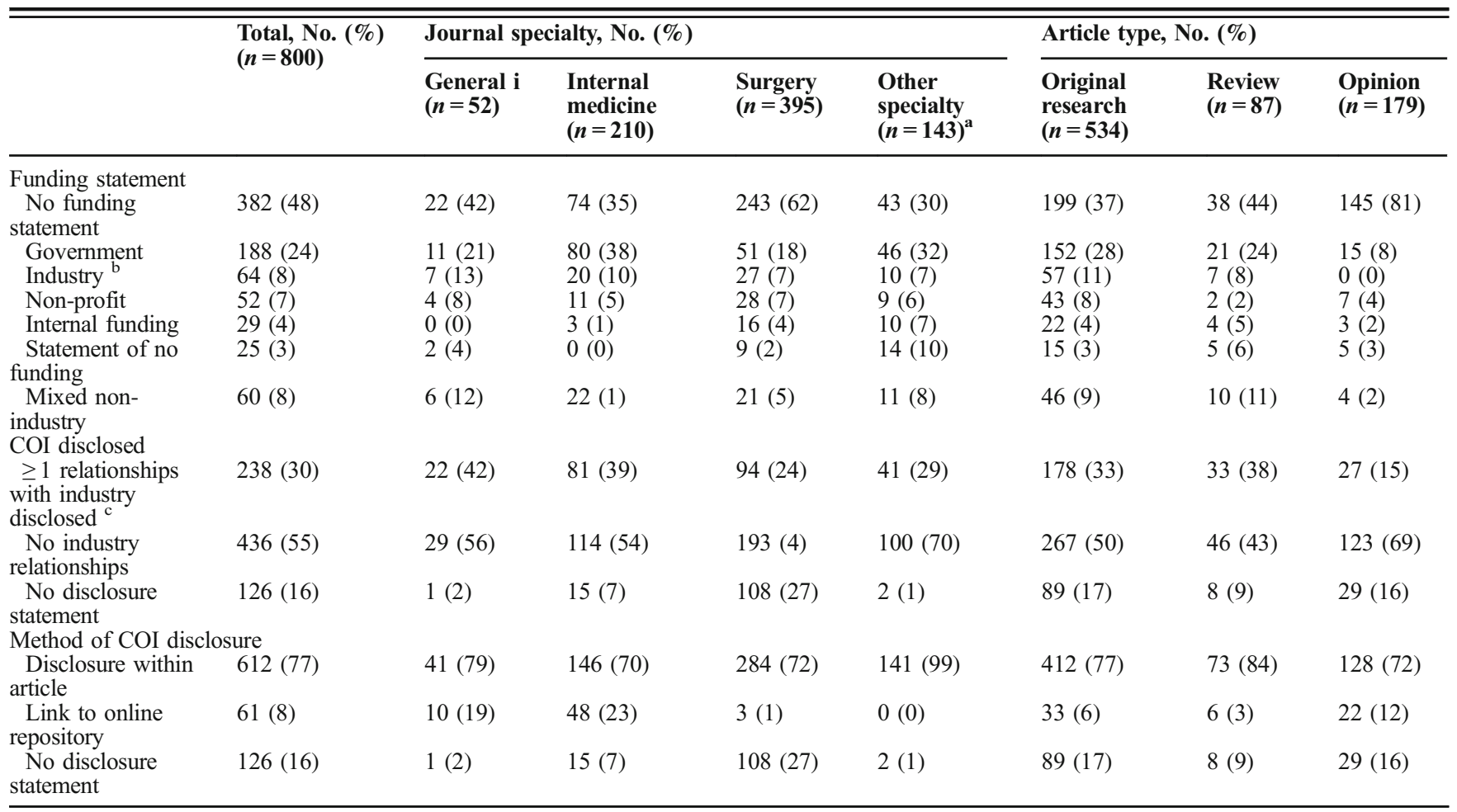

COI, conflict of interest

${ }^{a}$ Other specialties include anesthesiology, dermatology, emergency medicine, neurology, pediatrics, psychiatry, and radiology

${ }^{b}$ Industry funding including funding solely by industry and mixed funding including industry

${ }^{c}$ Per International Committee of Medical Journal Editor guidelines, only disclosures of relationships with "entities that could be perceived to be affected financially by the published work, such as drug companies, or foundations supported by entities that could be perceived to have a financial stake in the outcome" were considered positive COI disclosure. Financial relationships with other institutions such as government agencies, non-profit research foundations, medical journals, or academic institutions were not defined as conflicts for the purposes of this project 
We found that review and opinion articles were less likely to include funding statements than research articles. While research articles are often held to higher levels of scientific scrutiny than other article types, by design, opinion pieces and reviews are more subjective than research reports. Authors' viewpoints, which may be consciously or unconsciously influenced by financial relationships, should be interpreted by readers with the most complete information on potential biases possible.

We examined a cross-sectional subset of high-impact clinical journals which may not be generalizable to all clinical journals; however, high-impact journals may set editorial trends for other journals. Prior research suggests that lower impact journals are likely to have less complete COI policies; ${ }^{6}$ thus, our findings are likely conservative.

For disclosure to be an effective mechanism of managing COI, journal editors should standardize the inclusion of both COI and funding statements for all journal articles.

Corresponding Author: Timothy S. Anderson, MD, MAS; Division of General Internal Medicine University of California, San Francisco, San Francisco, CA, USA (e-mail: tsander1@bidmc.harvard.edu).
Conflict of Interest: All authors report no external funding for this work. Drs. Gellad and Anderson served on the Journal of General Internal Medicine editorial board during the conduct of this study. Dr. DeJong served as an editorial fellow at JAMA Internal Medicine during the conduct of this study.

\section{REFERENCES}

1. Institute of Medicine, Board on Health Sciences Policy. Conflict of Interest in Medical Research, Education, and Practice. Washington, DC: NAS Press; 2009.

2. Enhancing the QUAlity and Transparency Of health Research. EQUATOR Network. Accessed July 29th, 2019. https://www.equator-network.org.

3. Liu JJ, Bell CM, Matelski JJ, Detsky AS, Cram P. Payments by US pharmaceutical and medical device manufacturers to US medical journal editors: retrospective observational study. BMJ 2017;359:j4619.

4. Thomson Reuters. InCites Journal Citation Reports. Accessed: March $1^{\text {st }}$, 2017. https://jcr.incites.thomsonreuters.com.

5. American Association of Medical Colleges. Active Physicians in the Largest Specialties, 2015. Accessed: December 30th, 2016. https://www.aamc. org/data/workforce/reports/458480/1-1-chart.html.

6. Grundy 8, Dunn AG, Bourgeois FT, Coiera E, Bero L. Prevalence of Disclosed Conflicts of Interest in Biomedical Research and Associations With Journal Impact Factors and Altmetric Scores. JAMA 2018;319(4):408-409.

Publisher's Note Springer Nature remains neutral with regard to jurisdictional claims in published maps and institutional affiliations.

\section{Compliance with Ethical Standards:}

